\title{
Identification of Elite Restorers and Maintainers in Rice (Oryza sativa L.) Based on Pollen Fertility and Spikelet Fertility Studies
}

\author{
K. Rajendra Prasad ${ }^{1 *}$, K.V. Radha Krishna ${ }^{2}$, S. Sudheer Kumar ${ }^{2}$ and L.V. Subba Rao ${ }^{3}$ \\ ${ }^{1}$ Department of Genetics and Plant Breeding, College of Agriculture, Professor Jayashankar \\ Telangana State Agricultural University, Rajendranagar, Hyderabad-500030, Telangana, India \\ ${ }^{2}$ PJTSAU, Rajendranagar, Hyderabad-500030, Telangana, India \\ ${ }^{3}$ Crop Improvement Section, Indian Institute of Rice Research, Rajendranagar, Hyderabad- \\ 500030, Telangana, India \\ *Corresponding author
}

\section{A B S T R A C T}

Keywords

Oryza sativa, CMS lines, Pollen fertility, Restorer, Spikelet fertility, Testcrosses.

Article Info

Accepted:

21 June 2017 Available Online: 10 August 2017
A study was undertaken to elicit information on the identification of maintainers and restorers for their utilization in hybridization programme as the parental lines. Hybrid rice is the best practically feasible and readily acceptable options available to increase the production. For the development of viable, adoptable rice hybrids through utilization of cytoplasmic genetic male sterility, the processes of identification of maintainers and restorers involving local elite lines has become inevitable. A Total of thirty eight rice genotypes of diverse source of origin were test crossed with cytoplasmic male sterile (CMS) line IR79156A for the evaluation of the genotypes in order to identify potential restorers and maintainers. The $\mathrm{F}_{1}$ 's crossed between genotypes and CMS line expressed various degree of fertility reactions. Among the tested cytoplasmic male sterile genotypes, 18 genotypes expressed restorer $(\mathrm{R})$ reaction. Out of the remaining lines 17 genotypes were identified as partial restorers and 3 lines as partial maintainers.

\section{Introduction}

Rice occupies a premier place in Indian agriculture and plays a major role in Indian economy, being the staple food of two third of the population. More than $90 \%$ of the world's rice is grown and consumed in Asia, where $60 \%$ of the global populations live (Khush, 2005). The population in rice consuming countries continues to grow steadily and it is estimated that $40 \%$ more have to be produced by 2030 . China was the leading rice producer followed by India, Indonesia and Bangladesh in 2013-14; India was the largest exporter of rice in 2013-14 followed by Thailand Vietnam and USA, China was the leading importer in 2013-14 followed by Nigeria and Iran (United States Department of Agriculture). The dire need of increasing rice productivity and production encouraged rice scientists to develop and disseminate hybrid rice technology. Hybrid rice technology offers 
aviable option to meet this challenge. Rice hybrid for unfavorable environment can be developed using elite parental lines adapted to these environments.

The establishment of test cross nursery to identify restorers and maintainers is the first step in three line heterosis breeding (Akhter et al., 2008). Test cross programs help to identify maintainers as well as restorers. Maintainer lines are used for conversion into new CMS lines and restorer lines are subsequently used as male parent in hybrid development program. CMS lines introduced from elsewhere may not be well adapted to a given target area. Successful use of hybrid vigor in rice largely depends on availability of locally developed cytoplasmic genetic male sterile (CMS) and restorer lines.

\section{Materials and Methods}

During kharif, 2015 the CMS line IR-79156A was crossed with 38 diverse male fertile genotypes at IIRR, Rajendranagar, Hyderabad.

Three staggered sowing of the parents was undertaken at an interval of ten days to ensure synchronous flowering to produce adequate crossed seed. Twenty eight days old seedlings were transplanted with a spacing of $20 \times 15$ $\mathrm{cm}$. The recommended package of practices and need based plant protection measures were taken up to raise the healthy crop. Before crossing, the CMS line was tested for pollen sterility to ensure $100 \%$ pollen sterility of CMS line.

The panicles of CMS plant were bagged with butter paper before anthesis period. Pollen from pollen parents were dusted on bagged panicles of CMS line separately. So utmost care was taken while test crossing and crossed seeds from the combinations were collected for their evaluation.

\section{Estimation of pollen fertility}

Pollen fertility test of test cross $\mathrm{F} 1$ was carried out for their fertility or sterility responses. The spikelets (5 to 10) from the just emerged panicle of 3 randomly selected plants were collected in vial containing 70 percent ethanol. With the help of forceps, the anthers from the spikelets were placed on a glass slide containing $2 \%$ Iodine Potassium Iodide (IKI) strain. Then the anthers were gently crushed by using needle to release the pollen grains. After removing the debris, a covers lip was put on the slide and observed under microscope.

No. of fertile pollen grains

Pollen fertility $(\%)=$

Total no. of pollen grains

\section{Estimation of spikelet fertility}

Estimation was done on three panicles per plant (two selected at random and one from the main culm) from five randomly selected plants for each test cross hybrid at maturity. Spikelet fertility of hybrids was assessed by taking the count of well filled and chaffy spikelet in each panicle.

No. of filled spikelets

Spikelet fertility $(\%)=$-------------------- x 100

Total no. of spikelets

\section{Classification of pollen parents}

The pollen parents were classified into four categories-Maintainers (M), Partial Maintainers (PM), Partial Restorer (PR) and Restorer (R) based on the their pollen as well as their spikelet fertility percentages as presented in the following study. The following criteria for classifying the pollen parents were used as proposed by Virmani et al., 1997). 


\section{Results and Discussion}

The establishment of test cross nursery to identify restorers and maintainers is the initial step in three line hybrid rice breeding. The results showed that out of the attempted test crosses, 38 test crosses were successfully evaluated (Table 1). It was reported in some cases higher frequency of maintainers $(17 \%)$ than that of restorers (11\%) from 65 Testcrosses (Akhter et al., 2008). The pollen fertility percent of hybrids were varied from $39.60 \%$ to $88.00 \%$ and spikelet fertility ranged from 48.58 to $93.5 \%$. Similar observations have been reported by other researchers (Ali et al. 2014, Krishnalatha and Sharma 2012, Sharma et al., 2012). This variation may be due to the pollen fertility- restoring genes differ or their penetrance or expressivity differed with genotypes (Umadevi et al., 2010) or due to existence of modifiers genes. These hybrids were evaluated in Rabi 2015-16 for their spikelet and pollen fertility. Based on the hybrid evaluation, 18 genotypes were found to have effective restorability (spikelet fertility $>75 \%$ ), while 17 genotypes expressed partial fertility (50 to $75 \%$ spikelet fertility) and three were considered as partial maintainers (1 to $50 \%$ spikelet fertility). However using diverse CMS lines in testcrosses can give much validity to such fertility restoration studies (Das et al., 2013). These 18 genotypes (restorers) can contribute for the development of good hybrids by utilizing the masparental lines.

Classification of pollen parents

\begin{tabular}{|l|c|c|}
\hline Category & Pollen fertility (\%) & Spikelet fertility (\%) \\
\hline Maintainers & $0-1$ & 0 \\
\hline Partial maintainers & $1.1-50$ & $0.1-50$ \\
\hline Partial restorers & $50.1-80$ & $50.1-75$ \\
\hline Restorers & $>80$ & $>75$ \\
\hline
\end{tabular}

Table.1 Fertility restoration study for identification of restorers and maintainers among 38 lines test crossed with IR79156A

\begin{tabular}{|l|l|c|c|c|c|c|}
\hline $\begin{array}{c}\text { S. } \\
\text { No }\end{array}$ & \multicolumn{1}{|c|}{ Crosses } & $\begin{array}{c}\text { Days to } \\
\mathbf{5 0 \%} \\
\text { Flowering }\end{array}$ & $\begin{array}{c}\text { Pollen } \\
\text { fertility } \\
(\boldsymbol{\%})\end{array}$ & $\begin{array}{c}\text { Filled } \\
\text { grains/ } \\
\text { panicle }\end{array}$ & $\begin{array}{c}\text { Spikelet } \\
\text { fertility } \\
(\boldsymbol{\%})\end{array}$ & $\begin{array}{c}\text { Fertility } \\
\text { reaction }\end{array}$ \\
\hline 1. & IR-79156 A X KMR-3 & 98.00 & 88.00 & 168.00 & 93.50 & $\mathrm{R}$ \\
\hline 2. & IR-79156 A X TCP-718 & 97.00 & 80.90 & 148.18 & 92.71 & $\mathrm{R}$ \\
\hline 3. & IR-79156 A X TCP-783 & 87.00 & 82.60 & 120.66 & 91.92 & $\mathrm{R}$ \\
\hline 4. & IR-79156 A X TCP-795 & 91.00 & 85.60 & 136.25 & 91.64 & $\mathrm{R}$ \\
\hline 5. & IR-79156 A X TCP-801 & 93.00 & 86.30 & 167.71 & 90.42 & $\mathrm{R}$ \\
\hline 6. & IR-79156 A X PSV-15 & 95.50 & 88.40 & 167.80 & 90.10 & $\mathrm{R}$ \\
\hline 7. & IR-79156 A X PSV-41 & 94.50 & 83.90 & 175.43 & 89.31 & $\mathrm{R}$ \\
\hline 8. & IR-79156 A X PSV-49 & 93.50 & 91.50 & 162.00 & 88.75 & $\mathrm{R}$ \\
\hline 9. & IR-79156 A X TCP-950 & 93.50 & 89.50 & 117.65 & 87.76 & $\mathrm{R}$ \\
\hline 10. & IR-79156 A X TCP-951 & 91.50 & 84.90 & 107.00 & 86.28 & $\mathrm{R}$ \\
\hline 11. & IR-79156 A X TCP-960 & 85.00 & 80.70 & 158.28 & 86.33 & $\mathrm{R}$ \\
\hline 12. & IR-79156 A X TCP-963 & 93.00 & 83.90 & 160.32 & 86.09 & $\mathrm{R}$ \\
\hline 13. & IR-79156 A X TCP-964 & 90.00 & 82.50 & 183.00 & 85.07 & $\mathrm{R}$ \\
\hline
\end{tabular}




\begin{tabular}{|l|l|c|c|c|c|c|}
\hline 14. & IR-79156 A X TCP-661 & 97.00 & 87.90 & 141.33 & 81.54 & $\mathrm{R}$ \\
\hline 15. & IR-79156 A X TCP-585 & 94.00 & 85.00 & 124.33 & 78.09 & $\mathrm{R}$ \\
\hline 16. & IR-79156 A X TCP-657 & 94.00 & 84.70 & 171.00 & 77.39 & $\mathrm{R}$ \\
\hline 17. & IR-79156 A X SG-27-7-2 & 90.00 & 86.20 & 98.33 & 76.07 & $\mathrm{R}$ \\
\hline 18. & IR-79156 A X BK-49-53 & 101.00 & 80.60 & 169.70 & 75.65 & $\mathrm{R}$ \\
\hline 19. & IR-79156 A X AR-19-18 & 109.00 & 83.00 & 147.00 & 74.55 & PR \\
\hline 20. & IR-79156 A X L2-182 & 107.00 & 72.90 & 145.00 & 73.58 & PR \\
\hline 21. & IR-79156 A X TCP-650 & 95.00 & 77.40 & 132.25 & 71.47 & PR \\
\hline 22. & IR-79156 A X TCP-432 & 87.00 & 84.40 & 134.80 & 71.94 & PR \\
\hline 23. & IR-79156 A X ABU-10-82R & 92.00 & 69.20 & 176.00 & 71.47 & PR \\
\hline 24. & IR-79156 A X TCP-3005 & 106.00 & 62.80 & 184.50 & 70.53 & PR \\
\hline 25. & IR-79156 A X IB2-57 & 100.00 & 57.30 & 150.37 & 70.18 & PR \\
\hline 26. & IR-79156 A X BK-49-80 & 93.00 & 74.50 & 80.86 & 69.45 & PR \\
\hline 27. & IR-79156 A X KMP-128 & 88.00 & 56.00 & 118.33 & 69.32 & PR \\
\hline 28. & IR-79156 A X RPHR-517 & 92.00 & 65.80 & 111.00 & 66.38 & PR \\
\hline 29. & IR-79156 A X KMP-175 & 99.00 & 60.40 & 142.20 & 66.07 & PR \\
\hline 30. & IR-79156 A X SG-27-177 & 102.00 & 51.20 & 122.65 & 64.88 & PR \\
\hline & IR-79156 A X & 97.00 & 66.30 & 121.78 & 64.34 & PR \\
\hline 31. & AKSHAYADHAN & 87.00 & 60.60 & 74.93 & 55.50 & PR \\
\hline 32. & IR-79156 A X RPHR-1004 & 100.00 & 53.00 & 87.66 & 54.28 & PR \\
\hline 33. & IR-79156 A X JGL 17004 & 87.00 & 56.60 & 61.12 & 53.95 & PR \\
\hline 34. & IR-79156 A X ANJALI & 105.00 & 60.60 & 100.44 & 52.07 & PR \\
\hline 35. & IR-79156 A X RNR 21252 & 85.00 & 54.60 & 109.33 & 49.23 & PM \\
\hline 36. & IR-79156 A X NDR-3026 & 96.00 & 57.20 & 111.00 & 48.97 & PM \\
\hline 37. & IR-79156 A X SG-27-131 & 87.00 & 39.60 & 75.06 & 48.58 & PM \\
\hline 38. & IR-79156 A X VANDANA & & &
\end{tabular}

The findings of the present investigation revealed that fertility restoration reaction of the genotypes varies with their genetic background. More emphasis should be given to utilize popular rice cultivars in hybrid rice breeding as parental lines to achieve the goal of superior hybrid with better grain quality. The identified restorers are locally adopted. The identified maintainers can be developed as new members in cytoplasmic male sterile (CMS) family by repeated backcross breeding. However, in the present investigation no maintainers were being identified. The identified restorer lines can be used as pollen parent in developing new commercial hybrid varieties. New restorer may also be developed through crossing programme which can expand the genetic base of restorer by pyramiding complementary traits from diverse sources according to breeding objectives.

\section{References}

Akhter M, Zahid MA, Sabar Mnas Ahmad M. 2008. Identification of restorers and maintainers for the development of rice hybrids. Journal of Animal and Plant Science 18 (1):39-41.

Ali M, Hossain MA, Hasan MJ and Kabir ME. 2014. Identification of maintainer and restorer lines in local aromatic rice (Oryza sativa). Bangladesh Journal of Agricultural Research 39 (1):1-12.

Das P, Mukherjee B, Santra CK, Mukhopadhyay $S$ and Dasgupta $T$. 2013. Evaluation of genotypes for fertility restoring and maintaining behaviors in rice (Oryza Sativa L.). International Journal of Scientific and Technology Research 2 (11):228-232.

Khush S Gurdev, 2005. What it will take to feed 5.0 billion rice consumers in 2030 . 
Plant Molecular Biology. 59:1-6.

Krishnalatha S and Sharma D. 2012. Identification of maintainers and restorers for WA and Kalinga sources of CMS lines in rice (Oryza sativa L.). Electronic Journal of Plant Breeding 3 (4):949-951.

Sharma SK, Singh SK, Nandan R and Kumar M. 2012. Identification of restorers and maintainers for CMS lines of rice (Oryza sativa L.). Indian Journal of Plant Genetic Resource 25 (2):186-188.
Virmani, S.S., Viraktamath, B.C., Casal, C.L., Toledo, R.S., Lopez, M.T and Manalo, J.O. 1997. Hybrid rice breeding manual, International Rice Research Institute, Philippines.

Umadevi M, Veerabadhiran P, Manonmani S and Shanmuga Sundaram P. 2010. Identification of potential maintainers and restorers using cytoplasmic male sterile lines in rice. Electronic Journal of Plant Breeding 1 (4):948-952.

\section{How to cite this article:}

Rajendra Prasad, K., K.V. Radha Krishna, S. Sudheer Kumar and Subba Rao, L.V. 2017. Identification of Elite Restorers and Maintainers in Rice (Oryza sativa L.) Based on Pollen Fertility and Spikelet Fertility Studies. Int.J.Curr.Microbiol.App.Sci. 6(8): 2647-2651. doi: https://doi.org/10.20546/ijcmas.2017.608.315 